\title{
REFLECTION
}

\section{Promoting Healthy Lifestyles and Decreas- ing Childhood Obesity: Increasing Physician Effectiveness Through Advocacy}

\section{Jessica Schorr Saxe, MD}

Department of Family Medicine, Carolinas Medical Center, Charlotte, North Carolina

\begin{abstract}
Childhood obesity is a well-documented public health crisis. Even many children who are not overweight have inadequate physical activity, poor nutrition, excessive television and other screen time, or some combination thereof. The solution lies in the community. Environmental interventions are among the most effective for improving public health. In addition to addressing lifestyle issues in the office, physicians should advocate for environmental approaches. We can advocate at institutional, local, state, and federal levels through speaking, writing, and collaborating with others. In the United States, the timing is right to synergize with efforts such as the White House Task Force on Childhood Obesity and the Surgeon General's emphasis on changing the national conversation "from a negative one about obesity and illness" to a positive one about health and fitness.
\end{abstract}

Ann Fam Med 2011;9:546-548. doi.10.1370/afm.1263.

$\mathrm{O}$ ne would have to be Rip Van Winkle not to know that childhood obesity threatens the future of the next generation. Take your pick of alarming statistics: childhood obesity rates have more than tripled since 1980, with almost one-third of children aged 2 to 18 years now overweight or obese $36 \%$ of black and $38 \%$ of Hispanic children are affected ${ }_{i}$ and $28 \%$ of preschool aged children ${ }^{1}$ and $45 \%$ of children in poor families ${ }^{2}$ are overweight or obese.

Less well appreciated are the related issues that affect an even broader range of children. Of high school students, $63 \%$ do not meet recommended guidelines for physical activity, only $22 \%$ eat the recommended number of servings of fruits and vegetables, merely $14.5 \%$ drink 3 or more glasses of milk daily, and one-third watch 3 or more hours of television daily. ${ }^{3}$ These habits have a detrimental effect even on children who will never struggle with their weight.

Practicing physicians already see the consequences of obesity, not only in adults who develop cardiovascular disease and other sequelae as a consequence of having been overweight children, but also in obese children themselves who have an increased risk of type 2 diabetes, hypertension, sleep apnea, mental health problems, and orthopedic conditions. And the prediction that 1 in 3 children will eventually develop type 2 diabetes is dire. ${ }^{4}$ Stated another way, one-third of our population will be tethered to lancets, glucometers, medications, and visits not only to primary care physicians, but also to multiple specialists. They will live with risks of complications and premature death. Many physicians are aware of the clinical guidelines: to assess all children annually for weight status and body mass index for age, to evaluate dietary patterns and physical activity and sedentary behaviors at each well-child visit, to offer appropriate lifestyle 
messages to all children, and to deliver appropriate assessment, counseling, and treatment to children who are already overweight or obese. ${ }^{5}$

Yet, office-based solutions will not succeed in reversing the trend. This public health crisis resides in the community. Physicians and lay people who recognize this fact often respond with exhortations about the need to educate the public about good nutrition, physical activity, and limits on screen time. That this is not the solution should be intuitively obvious. Many adults remember being more active in childhood than children today (even if they did not walk 10 miles to school in the snow - uphill both ways) and eating less fat and sugar, fewer snacks, and more meals at home. Yet how many would attribute their better health practices to superior knowledge about nutrition or the value of physical activity? Most would say that those lifestyle "choices" were due to an environment that made them an automatic part of daily life.

Thomas Frieden, the director of the Centers for Disease Control and Prevention, has recently proposed a 5-tier pyramid of different types of interventions that provide a framework for public health action. ${ }^{6}$ Those interventions at the base of the pyramid benefit the greatest number of people. They "are generally the most effective public health actions." Counseling and education are in the apex of the pyramid, the 5 th and least effective tier, just behind individual clinical interventions, which rank 4 th. Addressing socioeconomic factors, such as poverty and education, occupies the base of the pyramid or 1st tier, and changing the environmental context to encourage healthy decisions is $2 \mathrm{nd}$.

The principle of changing the environment is to make default decisions healthy ones-for example, if healthy snacks are more available and less expensive, an individual will be more likely to choose them over junk food. Although industry often contends that a decline in personal responsibility is the source of obesity and that the solution is in individual decision making, Brownell et $\mathrm{al}^{7}$ have shown that other behaviors based on personal responsibility (such as condom use and alcohol avoidance among adolescents and abstinence from smoking among adults) have improved in the same time frame that obesity has increased. Tobacco use decreases with environmental interventions, such as smoke-free public places and work places, increases in cigarette taxes, and countermarketing advertising campaigns. ${ }^{8}$ Brownell and colleagues assert that, rather than being conflicting approaches, institutionalizing healthier default choices will promote both the adoption and maintenance of healthier lifestyles by individuals. ${ }^{7}$ This is not to say that public education is not needed. Having an informed public is always valuable-but education alone should not be expected to change behavior.

Although physicians have historically influenced health primarily through clinical interventions, there is evidence that they recognize the importance of community factors and are also interested in advocacy. In a survey of community clinicians in the Healthy Eating, Active Communities program, Boyle et al ${ }^{9}$ found that $90 \%$ believed that home or neighborhood environments were barriers to obesity prevention. In a cross-sectional survey of North Carolina pediatricians, Perrin et $\mathrm{al}^{10}$ found they perceived that the major barriers were environmental and that $87 \%$ of pediatricians were willing to play some role in policy change. In Charlotte, North Carolina, an e-mail survey of family physicians and pediatricians found that $85 \%$ of respondents were interested in learning to advocate for policies that would support healthy weights in children (J.S.S., A. Evans, MD, and L. Jenkins, MD, unpublished data, 2010).

The timing is opportune for physicians and other health care professionals to become engaged in promoting the health of the current generation of children and defying predictions that their life expectancies will be shorter than their parents'.

The White House Task Force on Childhood Obesity has released a report including 70 recommendations, covering early childhood, empowerment of parents and caregivers, healthier food in schools, access to healthy affordable food, and increasing physical activity. ${ }^{11}$ The report contains recommendations at various levels, including local institutions, industry, clinical practice, schools, and local, state, and federal government. Many are particularly apt for support by health professionals.

As physicians, we speak with authority and our opinions are respected in the community. We can advocate at a variety of points. We can encourage improved nutrition and physical activity in individual schools and in child care settings, especially those that our own children or patients attend. We can support policies that increase quality physical education and physical activity in schools ${ }^{11,12}$ at a local level through discussions with the school board or school system staff or by serving on School Health Advisory Councils. Many organizations, such as Eat Smart, Move More NC, provide tool kits with a wealth of materials outlining guidelines, curricula, and tips. ${ }^{13}$ We can advocate for our hospitals to adopt the Baby Friendly Hospital Initiative $^{12,14}$ to promote breastfeeding and encourage them to implement healthy eating policies for employees, patients, and visitors. We can address the built environment by seeing that our communities are planned to be walkable and bikeable, and provide opportunities for physical activity for all ages and income levels. 
At a higher level, we can advocate for state and national legislation improving school nutrition and access to healthy foods, ${ }_{1}^{11}$ and restricting food advertising targeted at children. Our perspectives on the health aspects of these policies are unique. Telling stories from our practices-for example, about overweight children who do not spend time outside because they lack safe places to play in their neighborhoods-may capture the attention of legislators weary of dry statistics.

Although time is often perceived as a barrier to advocacy, it does not have to be prohibitive. We can talk to officials or legislators, speak at city council or school board meetings, write occasional guest columns or letters to the editor for our local newspapers, collaborate with public health professionals who provide technical expertise while we provide stories, and/or participate in organizations that share our interests without making a big dent in time for our practices or families.

And it will be a worthwhile investment. Primary care interventions, although recommended, are woefully inadequate, ${ }^{15}$ whereas community interventions show promise in reversing the ominous trend of increasing obesity.

We may thus heed the call of Risa Lavizzo-Mourey, president of the Robert Wood Johnson Foundation, to physicians to treat the community at large and, citing the Institute of Medicine's ecologic model, to "leverage their clinical interventions in the examination room by intervening in the patient's larger world for improvements in child and adolescent health that will improve the overall community's health status." ${ }^{\prime 16}$

US Surgeon General Regina Benjamin, a family physician, wants to "change the national conversation from a negative one about obesity and illness to a positive conversation about being healthy and fit." ${ }^{17}$ By engaging with the community to effect environmental and policy change, we physicians will be in the vanguard of advancing this vision to ensure the health of the next generation.

To read or post commentaries in response to this article, see it online at http://www.annfammed.org/content/9/6/546.

Key words: Childhood obesity; physician advocacy; environmental change; public health

Submitted September 22, 2010; submitted, revised, January 7, 2011; accepted January 25, 2011.

Acknowledgments: I would like to thank Alice S. Ammerman, DrPH, RD, Professor, Department of Nutrition, Gillings School of Global Public Health, Director, Center for Health Promotion and Disease Prevention, University of North Carolina at Chapel Hill; Michael Dulin, MD, PhD,
Director of Research, Carolinas Medical Center Department of Family Medicine; Mary K. Goldstein, MD; and James Dabney Miller, JD, MPH, Visiting Scholar, Department of Health Policy and Management, Johns Hopkins Bloomberg School of Public Health, for helpful comments on earlier versions of this manuscript. They received no compensation.

\section{References}

1. Ogden $C L$, Carroll MD, Curtin LR, Lamb MM, Flegal KM. Prevalence of high body mass index in US children and adolescents, 2007-2008. JAMA. 2010;303(3):242-249.

2. Bethell C, Simpson L, Stumbo S, Carle AC, Gombojav N. National, state, and local disparities in childhood obesity. Health Aff (Millwood). 2010;29(3):347-356.

3. Eaton DK, Kann L, Kinchen S, et al; Centers for Disease Control and Prevention (CDC). Youth risk behavior surveillance-United States, 2009. MMWR Surveill Summ. 2010;59(5)(SS-5):1-142. http://www. cdc.gov/mmwr/pdf/ss/ss5905.pdf. Accessed Aug 4, 2010.

4. Narayan KMV, Boyle JP, Thompson TJ, Sorensen SW, Williamson DF. Lifetime risk for diabetes mellitus in the United States. JAMA. 2003;290(14):1884-1890.

5. Barlow SE; Expert Committee. Expert committee recommendations regarding the prevention, assessment, and treatment of child and adolescent overweight and obesity: summary report. Pediatrics. 2007;120(Suppl 4):S164-S192.

6. Frieden TR. A framework for public health action: the health impact pyramid. Am J Public Health. 2010;100(4):590-595.

7. Brownell KD, Kersh R, Ludwig DS, et al. Personal responsibility and obesity: a constructive approach to a controversial issue. Health Aff (Millwood). 2010;29(3):379-387.

8. Hopkins DP, Husten CG, Fielding JE, Rosenquist JN, Westphal LL. Evidence reviews and recommendations on interventions to reduce tobacco use and exposure to environmental tobacco smoke: a summary of selected guidelines. Am J Prev Med. 2001;20(2 Suppl):67-87.

9. Boyle M, Lawrence S, Schwarte L, Samuels S, McCarthy WJ. Health care providers' perceived role in changing environments to promote healthy eating and physical activity: baseline findings from health care providers participating in the healthy eating, active communities program. Pediatrics. 2009;123(Suppl 5):S293-S300.

10. Perrin EM, Flower KB, Garrett J, Ammerman AS. Preventing and treating obesity: pediatricians' self-efficacy, barriers, resources, and advocacy. Ambul Pediatr. 2005;5(3):150-156.

11. Barnes $M$; and the White House Task Force on Childhood Obesity. Solving the Problem of Childhood Obesity within a Generation. May 2010. http://www.letsmove.gov/pdf/TaskForce_on_Childhood_ Obesity_May2010_Full Report.pdf. Accessed Aug 4, 2010.

12. Institute of Medicine. Local Government Actions to Prevent Childhood Obesity. Washington, DC: The National Academies Press; 2009.

13. Eat Smart, Move More NC [Web site]. http://www.eatsmartmovemorenc.com. Accessed Jan 2, 2011.

14. Baby-Friendly USA [Web site]. http://www.babyfriendlyusa.org/. Accessed Jan 2, 2011.

15. Wake M, Baur LA, Gerner B, et al. Outcomes and costs of primary care surveillance and intervention for overweight or obese children: the LEAP 2 randomised controlled trial. BMJ. 2009;339:b3308.

16. Lavizzo-Mourey R. Childhood obesity: what it means for physicians. JAMA. 2007;298(8):920-922.

17. Hearings Before the Senate Committee on Health. Education, Labor and Pensions, 111 Cong, 2nd Session. Mar 4, 2010; statement of Regina M. Benjamin, MD, MBA, Surgeon General. http://help.senate.gov/imo/media/doc/Benjamin.pdf. Accessed Aug 4, 2010. 